\title{
The Belgian Coastal Atlas: moving from the classic static atlas to an interactive data-driven atlas
}

\author{
Hannelore Maelfait • Kathy Belpaeme
}

Received: 23 December 2008 /Revised: 15 September 2009 / Accepted: 22 September 2009 /Published online: 27 October 2009

(C) Springer Science + Business Media B.V. 2009

\begin{abstract}
The Belgian Coastal Atlas was first published in hardback in 2004, with no intention to move towards a web version. The many requests for maps encouraged the developers to launch a web-based atlas in 2005. The interactive-nature of the maps was kept simple and the look of the maps was considered more important than the possibilities that GIS applications offered. Three years on, the Coordination Centre on ICZM would like to move from the more or less static web atlas to an interactive data-driven atlas, where sustainability indicators for the coast play a prominent role. The final product will be a policy supporting tool that will back the ICZM process for a wide range of coastal actors, planners and managers.
\end{abstract}

Keywords Atlas · Coast · Indicators · GIS · Sustainability

\section{Introduction}

In the online encyclopaedia Wikipedia (http://en.wikipedia. org/wiki/Atlas), an atlas is defined as an overview of maps or images, or a combination of both. It is traditionally bound in book form, but it is also found in multimedia formats. For online atlases, the range of formats has expanded thanks to technology that provides a wide range of new opportunities like web-applications and Geographic Information Systems (GIS).

A web atlas can take the form of a static collection of maps with explanatory text (Fig. 1). An example of this is a

H. Maelfait $(\bowtie) \cdot$ K. Belpaeme

Coordination Centre on Integrated Coastal Zone Management,

Wandelaarkaai 7 ,

8400 Oostende, Belgium

e-mail: hannelore.maelfait@kustbeheer.be map database of the province of Limburg, with attractive static maps available for all users (http:/www.limburg.be/ eCache/17585/Kaartenbak.html). In other cases, like the marine Irish digital atlas MIDA (http://mida.ucc.ie/), it is a resource for spatial data and information, specifically Ireland's coastal and inshore marine areas. The core is formed by a web-based GIS system. MIDA currently hosts over 100 data layers, delivered by more than 30 organizations. So it is GIS driven and its design required the collaboration of a variety of initiatives and institutes.

Strongly driven by available scientific data, the principal objective of the African Marine Atlas is to collect available geospatial datasets and information on the marine environment for coastal resource managers and planners (http://www. africanmarineatlas.net/). The focus is on scientific outcome with less emphasis being placed on the look of the maps.

Other atlas-like initiatives refer instead to an "explorer", like the Dorset Explorer or the North Coast Explorer within the Oregon Coastal Atlas (http://www.coastalatlas.net/). The Explorer provides information through an interactive website to help local citizens and policy makers make better decisions or gain a better understanding of the coast. They sometimes offer different types of tools like "find my nearest", coastal inundation visualisation, assessment tools, a glossary and a directory of (historical) coastal photographs.

There have been significant developments in national and regional coastal atlases based on web-applications and Geographic Information Systems (GIS) in various countries worldwide. These internet-based resources are of great value to decision-makers, scientists and indeed anyone in the general public who has an interest in coastal issues.

One atlas that has proved valuable to both decision-makers and the general public is the atlas of the Belgian Coast. This article will focus on the development and the future of the Belgian Coastal Atlas (Belpaeme and Konings 2004). 


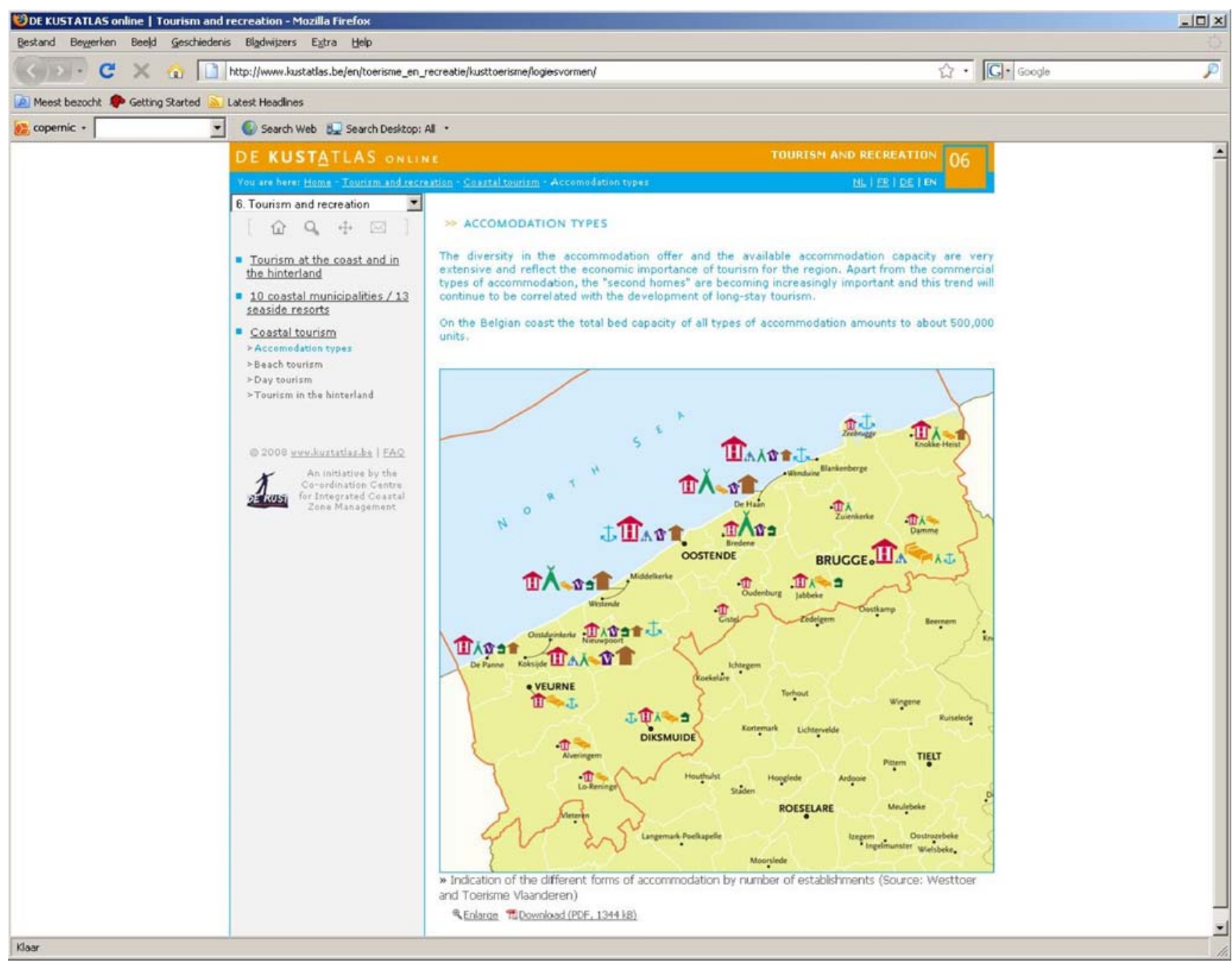

Fig. 1 An example of a static webpage: showing a map and explanatory text. (http://www.kustatlas.be/nl/toerisme_en_recreatie/toerisme_aan de_kust_en_in_het_hinterland/map/?id=9\&lan=nl)

The Belgian Coastal Atlas was an initiative of the Coordination Centre on Integrated Coastal Zone Management (www.kustbeheer.be). It was published in October 2004 with a view to reporting to the European Commission on the state of the Belgian coast in relation to the ICZM recommendation (EU COM (2002) 413 Recommendation of the European Parliament and of the Council of 20 May 2002 concerning the implementation of Integrated Coastal Zone Management in Belgium, 2002/413/EC). The printed atlas was designed to attract a broad audience, including scientists, politicians, fishermen and the wider public. The book was sold in bookshops along the Belgian Coast.

The printed version of the atlas, of which 1,000 Dutch and 500 English copies were produced, was sold out in about 4 months. And today, 4 years on, the Coordination Centre still receives requests from professionals and the public for copies of the atlas or for using specific maps from the atlas.
A decision was taken to produce an online version of the atlas. This web version was launched in November 2005 and has proven successful (www.kustatlas.be). Even though there is no active publicity to promote the online atlas, the number of visitors per month is very satisfying. On average the site has 2,000 hits per month (an average of about 70 people per day) of which more than $50 \%$ are Belgian visitors. In comparison, the Irish digital atlas MIDA had on average 600 visitors per month in 2006 .

\section{Use of GIS in the Belgian Atlas}

For the development of the online atlas the Coordination Centre on ICZM collaborated with three private partners: Aquaterra (http://www.aquaterra.be/nl/) for the geographic information, map digitisation and content of the atlas, Five to Nine (http://www.quoted.be/) for the website 
development and Magenta (http://www.magenta.be/) for the design.

The goal was to create an easily accessible, simple, userfriendly atlas that offered the options of printing good quality maps and using the maps in presentations. The website was set up in compliance with web standards current at the time (2005) and is therefore easy to consult with the more commonly used browsers that support the standards. The website was set up in $\mathrm{php} / \mathrm{html}$ and for the interactive maps flash applications and Actionscripts were used. All maps can be downloaded in PDF format and the data is in excel format. For some maps Shape files are provided. The maps were designed with graphic software and uploaded to the site as vectorial graphics. More information on the atlas, the technical and data-related matters, the system design, and statistics on the usage will be published in the "Handbook of Research on Coastal Informatics: Web Atlas Design and Implementation" (published by IGI Global, in preparation).

The existing mapping services are extensive, and a choice has to be made regarding which services to provide the visitor. In 2005, when developing the web atlas, static maps were chosen because GIS maps did not allow for an appropriate lay-out at that time. Because the atlas's main objective was to distribute information to a broader public and to policy makers, the look of the maps was considered more important than the interactivity (Fig. 2).

With the limited resources that the Coordination centre had at its disposal in 2006, extra interactivity was added to the Belgian Coastal Atlas with the assistance of Flanders Marine Institute. A selection of GIS layers were developed and a test case combining GIS and Google earth was developed.

GIS has a great deal of potential for use in atlases. It provides a very effective means to convey graphically complex information. Although GIS was not used much in the Belgian Coastal Atlas the Coordination Centre on ICZM had been using GIS maps frequently to present geographically the data and trends for the sustainability indicators for the coast (Fig. 3).

The atlas contains a limited set of aggregated data, but by linking the atlas to the databases of the sustainability indicators for the coast, a rich set of data was added. All the data used in the atlas is 'open source' data, mostly provided by public authorities and their administrations. These authorities gather the information themselves within their objectives and policies, or the data is generated by universities, consultants or other institutions commissioned by the authorities. None of the data was paid for. As the information is all publicly available, no licensing or data release issues apply. The indicators are in themselves often aggregated data, but a combination of relevant datasets, they can explain more about the state of the coast and whether the coast is moving forward in a sustainable way (Maelfait and Belpaeme 2007).

The advantages of using GIS maps for visualizing the coastal sustainability indicators are:

- visualising differences between regions;

- visualising trends and patterns;

- through layering, studying combined information and relationships between indicators.

- creating maps that are easier for a non-technical audience to understand than tables or graphs.

\section{Discussion: the future: from a static atlas to an interactive explorer}

Although the static atlas still attracts many visitors, the Coordination Centre on ICZM wants to move towards a more interactive, data-driven atlas. The static website has to be up dated with the newest information and there is a need amongst stakeholders for more accurate data, and dynamic customised maps. The new available techniques make it possible to update the atlas more regularly and keep it attractive and interactive at the same time. The main aim of the Coordination Centre on ICZM is to make the atlas a more dynamic tool for the general public, but also for coastal planners.

This upgrade has to be considered carefully. The starting point will be an analysis of the current use and the wishes. The first results of this analysis show that users of the atlas appreciate it a great deal. Visitors are especially pleased with the layout of the maps and the ease of navigating the website. Also, the simplicity and the fact that visitors are not overwhelmed by information to choose from is appreciated. The link with the sustainability indicators has a great deal of potential to add extra information to the atlas. The fact that the coastal atlas also contains information on the land and the sea side of the coast, where some atlases only consider the land or the sea side, is considered very useful (Provincie West-Vlaanderen 2009). More details on this will be published in the "Handbook of Research on Coastal Informatics: Web Atlas Design and Implementation" (published by IGI Global, in preparation).

Furthermore it will be important to (re)consider the definition of the target audience.

In the case of the Belgian Coastal Atlas, the target audience of the first online version was the general public. With the update, the planners and coastal managers have been included. This will require the inclusion of more tools, like indicators, data analysis, accurate and reliable maps and relevant background information.

Before starting the development process of the updated version, it is also important to map the needs of the end- 


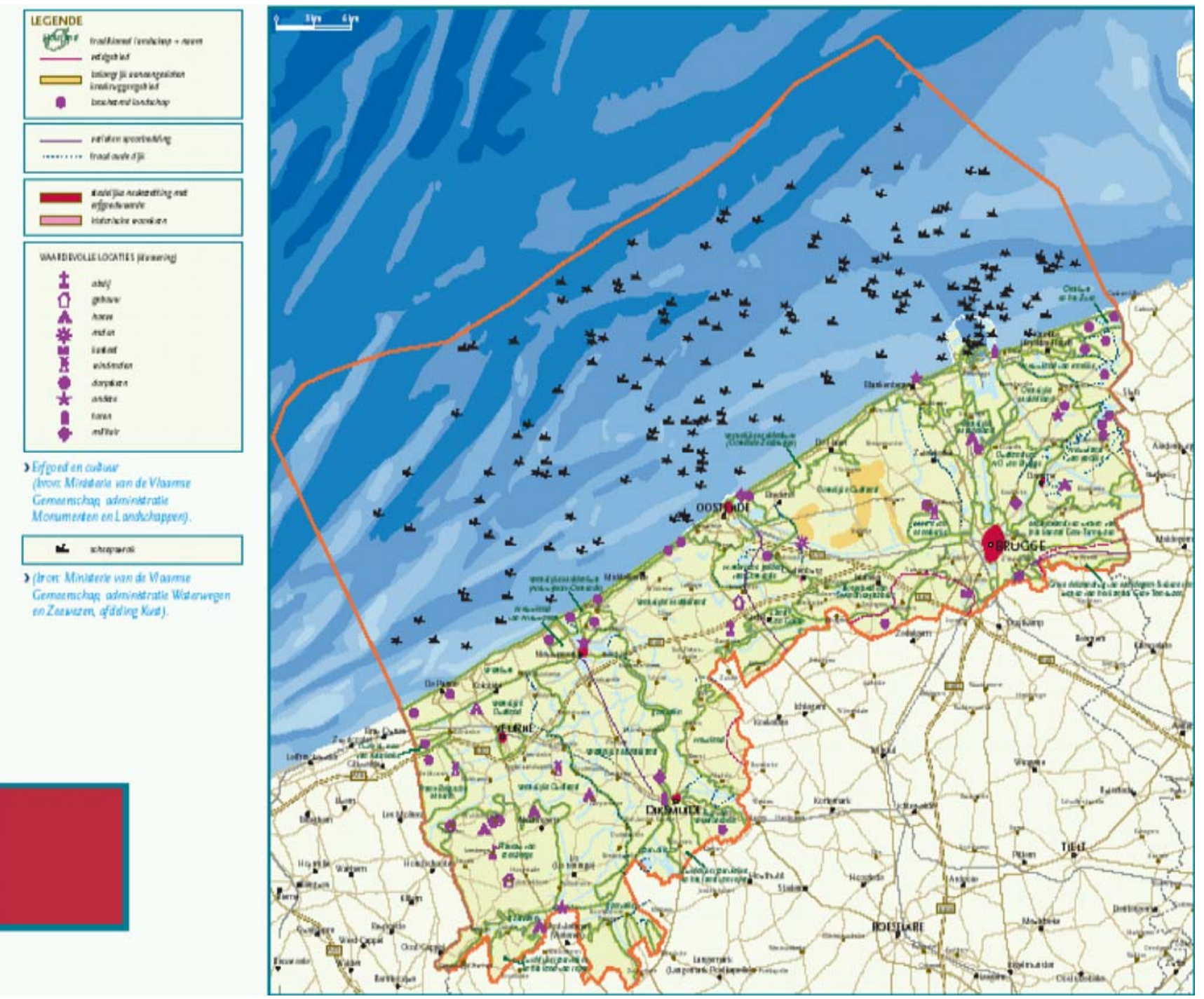

Fig. 2 Map designed in graphical application, showing culturally important assets on the Belgian coast

user. What does the end-user lack to make coastal work more efficient? What does the end-user expect of an atlas? If an atlas tool is developed without meeting the needs of the end-users, the atlas might look good and contain interesting information, but there is a risk that it will not be as useful as it could be.

The end-product will also depend on the purpose/aim of the updated atlas. The Belgian Coastal Atlas project was initiated to respond to the EU Recommendation on ICZM. Although the target audience of this report could be quite narrow (experts), in Belgium the approach was taken to target the wider public as well (IMIS 2008). With the update, the Coordination Centre aims to develop the Belgian Coastal Atlas as an interactive tool for policy makers and as an information tool for coastal stakeholders and members of the wider public interested in making use of GIS and other mapping tools.
A real challenge for the coastal atlas is to target an integration of sector or thematic information (Kahane et al. 2009). But the purpose will not be one of being comprehensive. At present the Belgian Coastal Atlas includes eight thematic chapters and four that are more general. The sustainability indicators will be explored as tools to improve integration of data. The data will be visualised geographically where possible and relevant. The indicator maps will be data driven, giving information with the greatest level of detail. The visitor will be able to carry out queries or use filters on the maps and the data. In doing so, the Belgian Coastal Atlas aims to move towards a type of "Coastal Explorer" which can support planners, managers, scientists, etc. in their work or in decision making.

Within the update, the coordination centre will look at the newest techniques available for presenting maps and graphs. It is possible to develop the new online atlas in 


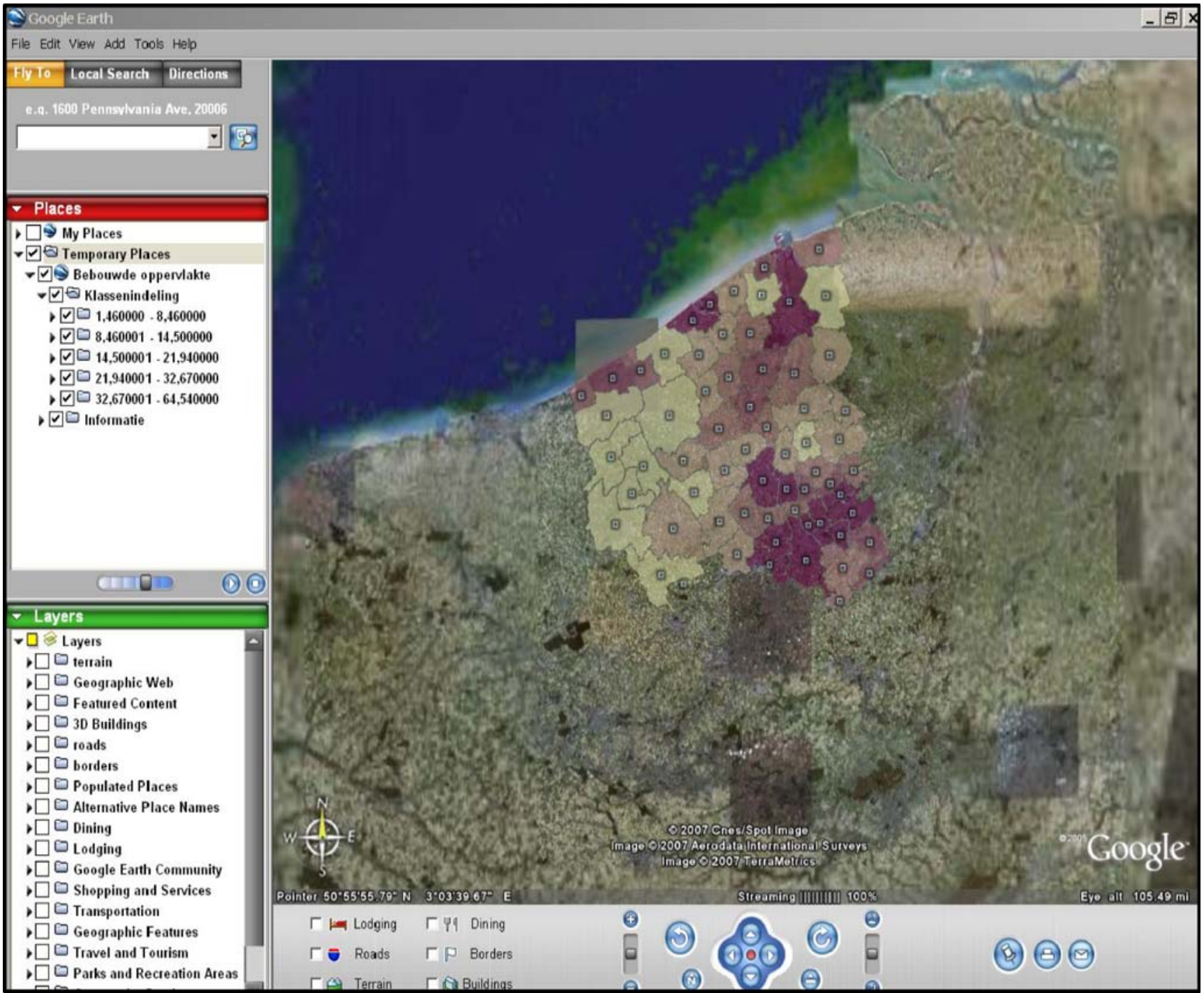

Fig. 3 Results of the sustainability indicator on population density presented using Google earth and GIS

compliance with the current standards like OGC and INSPIRE. Nevertheless within the process of the update, a balance will be struck between attractiveness, comprehensiveness and interactivity.

\section{The developments of the Belgian Coastal Atlas, viewed in a European context}

The development of the Belgian Coastal Atlas is considered within a wider European and International framework. In 2007, important policy decisions were taken and policy developments took place in Europe regarding the management of coastal, marine and maritime resources. After 2 years of negotiations, the European Union agreed upon a marine environmental law (Marine Strategy Framework Directive, MSFD), which aims at achieving 'good environ- mental status' in the marine environment by 2020 (EU COM (2007)456 FINAL).

Furthermore, in October 2007 the communication "An Integrated Maritime Policy for the European Union" (COM (2007) 575 final) was published by the European Commission.

This communication highlights the importance of atlases and the Commission has decided to launch a European Atlas of the Seas in 2009 as an educational tool and as a means of underlining Europe's common maritime heritage. The development of an integrated tool should make the holistic nature of the maritime environment visible and should contribute to raising the awareness of citizens and stakeholders for whom an integrated approach to maritime policy is self-evident. The development of an EU Atlas of the Seas should demonstrate the relevance of setting up an integrated data network, and the importance of the crosssectoral accessibility of such data. 
The Belgian Coastal Atlas will contribute to the implementation of the Integrated Maritime Policy. The development of the atlas tackles the concern of the European Commission mentioned in the communication on a Maritime Policy for Europe that "much information is available about Europe's Oceans and about maritime activities, but there is a lack of published material bringing it all together in a form that would allow the general public, those interested in the sea, and young people at school to get to know the maritime world." (COM (2007) 575 final).

The Coordination Centre has been involved at a European level in the discussions on coastal (web) atlases. This topic is also high on the agenda of the European Environment Agency (EEA), who organised a conference on coastal atlas development in July 2008 (http://ican. science.oregonstate.edu/ican3 prog). The Belgian Coastal Atlas was presented as a case study at this conference. With this conference the EEA wanted to help shape the design, functioning and sharing of coastal and marine information services in the coming years. To this end, the EEA, together with the member countries, the Regional Seas Conventions and the European Commission, has initiated several activities that will benefit greatly from the realisation of coastal/marine mapping projects.

Also an integration or at least fine-tuning exercise at international level is needed. For this, the Coordination centre is involved in the International Coastal Atlas Network (ICAN) (http://ican.science.oregonstate.edu/about_ican) network from the very beginning and is an active member of this network.

Established in 2007, this informal group is a network of organizations who have been meeting over the past 2 years to investigate and implement data interoperability approaches to coastal web atlases (CWAs). The mission/ strategic aim of ICAN is to share experiences and to find common solutions to Coastal Web Atlas (CWA) development (e.g., user and developer guides, handbooks and articles on best practices, information on standards and web services, expertise and technical support directories, education, outreach, and funding opportunities, etc.), while ensuring maximum relevance and added value for the end users. The long-term view is for global-level operational interoperability which will evolve as the ICAN community strives to increase awareness of the opportunities that exist for increased coastal and marine data sharing among policy makers and resource managers as strategic users of a CWA. ICAN participants play a leadership role in forging international collaborations of value to the participating countries and optimizing regional governance in coastal zone management. A major goal is to help build a functioning digital atlas of the coast worldwide based on the principle of shared distributed information. ICAN will organize a cooperative interoperability network for the integration of locally maintained CWAs as the premier source of spatial information about coastal zones throughout the world.

The Coordination centre helps shape the future strategy of ICAN and contributes actively to the Network action plan.

\section{Conclusion}

The Belgian Coastal Atlas was first published as a book, and was translated into a web-application only in a second phase. (Re)Designing web-atlases requires a great deal of thought before starting. Many different approaches can be taken and the final product can take many forms. The degree of interactivity, the use of GIS or other mapping applications will depend on the aim and on the target audience of the atlas. A close collaboration between managers and scientists is needed to produce a useful but scientifically sound management support tool. International cooperation between atlas developments worldwide is important to tease out the best of all atlas developments.

Acknowledgements The authors wish to thank Flanders Marine Institute (www.vliz.be) for their technical support, for hosting and maintaining the online atlas and for the collaboration concerning the sustainability indicators for the coast.

Special thanks also goes to Aquaterra and Quoted for the design and development of the atlas.

We are grateful to the partners of the Coordination centre on ICZM and the European Commission for providing the funds to realise the Belgian Coastal Atlas.

\section{References}

African Marine Atlas http://www.africanmarineatlas.net/ Consulted on 1 September 2009

Aquaterra http://www.aquaterra.be/nl/ Consulted on 10 September 2009

Belpaeme K, Konings Ph (2004) De kustatlas Vlaanderen-België. Coordination Centre on Integrated Coastal Zone Management, Ostend, p 99

De Kustatlas http://www.kustatlas.be/ Consulted on 10 September 2009

EU COM (2002) 413. Recommendation of the European Parliament and of the Council of 20 May 2002 concerning the implementation of Integrated Coastal Zone Management in Belgium, 2002/413/EC

EU COM (2007) 456 FINAL; COMMUNICATION FROM THE COMMISSION TO THE EUROPEAN PARLIAMENT pursuant to the second subparagraph of Article 251 (2) of the EC Treaty concerning the Common position of the Council on the adoption of a European Parliament and Council Directive establishing a Framework for Community Action in the field of Marine Environmental Policy (Marine Strategy Framework Directive)2005/0211 (COD)

Five to Nine http://www.quoted.be Consulted on 10 September 2009

Flanders Marine Institute http://www.vliz.be/ Consulted on 10 September 2009 
International Coastal Atlas Network (ICAN) (http://ican.science. oregonstate.edu/about ican)

IMIS, Integrated Marine Information System. Available online at http://www.vliz.be/imis/imis.php?module=institute. Consulted on 3 March 2008.

Kahane L, de Laat W, Myncke R, Staelens P (2009) Second sojourn at the coast: applied research on the littoral profile, the effects and toolkit for sound coastal policy (original title:Tweede verblijven aan de Kust: onderzoek naar het profiel, de effecten en een toolkit voor het beleid). Idea Consult, Brugge, p 39

Maelfait, H., Belpaeme K. Ed. (2007). The Coastal Compass, key indicators as guidelines for ICZM. Ostend, Belgium. Coordination Centre for Integrated Coastal Zone Management, 63 pp.
Magenta http://www.magenta.be/ Consulted on 10 September 2009 Marine Irish Digital Atlas http://mida.ucc.ie/ Consulted on 30 Augustus 2009

Oregon Coastal Atlas http://www.coastalatlas.net/ Consulted on 10 September 2009

Provincie West-Vlaanderen (2009) West-Flanders: social and economic facts and figures 2009 (original title: West-Vlaanderen sociaal economisch-feiten en cijfers editie 2009). Provinciebestuur WestVlaanderen, Brugge, p 164

Provincie Limburg http://www.limburg.be/eCache/17585/Kaartenbak. $\mathrm{html}$ Consulted on 10 September 2009

Wikipedia http://en.wikipedia.org/wiki/Atlas Consulted on 10 September 2009 